\title{
Prevalence of Plasmodium spp. and helminths: Systematic review 2000-2018
}

\begin{abstract}
Introduction: The parasites that cause malaria and helminthiases are distributed in the same geographical areas, affect the same groups and share risk factors; however, its coinfection is little studied.

Objective: To estimate the global and specific prevalence by species of Plasmodium spp., Helminths and their coinfection based on studies published in the world scientific literature, 2000-2018.

Methodology: Systematic review of the scientific literature based on studies published in Pubmed, Science Direct, SciELO, Web of Science, EBSCO and Google Scholar. Investigations were included based on the implementation of a search protocol that included inclusion and exclusion criteria, according to the PRISMA guide. Reproducibility of the search and selection of studies was guaranteed. The methodological quality was evaluated with STROBE.

Results: We included 61 articles with a population of 45,060 people, mostly from Africa, with children and pregnant women. 51 evaluated coinfection in the general population and 10 analyzed helminth infection in a population with malaria. The prevalence of malaria was $41 \%$, helminths $43.4 \%$ and the coinfection $17.2 \%$. The most prevalent species were Plasmodium falciparum, Schistosoma haematobium, Uncinarias and Ascaris Lumbricoides. The coinfection between Plasmodium falciparum and Uncinarias was the most prevalent with $6.1 \%$ in the general population and $28 \%$ in people with malaria.

Conclusion: We found a high prevalence of coinfection in a small number of studies, which shows that the study of the interactions between Plasmodium and helminths is an undeveloped area in parasitology. Despite the high magnitude of malaria and helminths in the Americas, studies of coinfection in the region are scarce, which constitutes an obstacle to impact its clinical and epidemiological effects, while preventing the development of public policies for parasitological control in endemic areas.
\end{abstract}

Keywords: malaria, helminths, coinfection, prevalence, Plasmodium spp, geohelminths
Volume 9 Issue 4 - 202I

\author{
Santiago Gallego Agudelo,' Ana Luz Galván \\ Diaz, ${ }^{2}$ Jaiberth Antonio Cardona-Arias ${ }^{3}$ \\ 'Estudiante Microbiología y Bioanálisis, Grupo de investigación \\ Microbiología Ambiental, Escuela de Microbiología, Universidad \\ de Antioquia, Colombia \\ ${ }^{2}$ Bact, MSc Ciencias Básicas Biomédicas, PhD Microbiología y \\ parasitología, Universidad de Antioquia, Colombia \\ ${ }^{3}$ MyB, MSc Epidemiología, MSc Economía aplicada, PhD (c) Salud \\ Pública, Escuela de Microbiología Universidad de Antioquia, \\ Colombia
}

Correspondence: Ana Luz Galván Diaz. Calle 67 Número 53-108, Bloque 5, oficina 410, Medellín, Colombia, Tel 215495, Fax 2195486, Email ana.galvan@udea.edu.co

Received: June 16, 2021 | Published: July 15, 2021

\section{Introduction}

Malaria is a disease transmitted to humans by the bite of infected female mosquitoes, of the genus Anopheles, it is caused by parasites of the genus Plasmodium spp. and the species that infect humans are Plasmodium falciparum; Plasmodium vivax; Plasmodium malariae; Plasmodium ovale. Plasmodium knowlesi and recently Plasmodium cynomolgi, the first two being the most prevalent. ${ }^{1}$ The symptoms of malaria occur due to the invasion of the parasites into the erythrocytes where they reproduce and cause their lysis, generating tissue anoxia, immune mechanisms such as fever and immune complexes, bleeding disorders and anemia also occur. ${ }^{2}$

According to the World Malaria Report, there were 216 million cases of malaria in 2016, compared with 211 million in $2015^{1}$ and the estimated number of deaths from malaria was 445,000 , similar to that of $2015(446,000)$. The African continent recorded $90 \%$ of the cases and $91 \%$ of the deaths from this cause, and 15 countries in the subSaharan region reported $80 \%$ of the burden of the disease. ${ }^{3}$ The living conditions of people who inhabit malaria endemic places converge with areas of high risk or susceptibility to contracting helminth infection, for example, the storage of water in tanks or wells can be contaminated with the infectious forms of some helminths as well that favor the reproduction of the malaria vector. To this are added other links of epidemiological and clinical type, by sharing some environmental, sociodemographic and economic risk factors; affect the same type of subgroups and cause effects that can aggravate the clinical condition of susceptible populations such as children and pregnant women. ${ }^{3}$

In this sense, helminthiases are one of the most common parasites in the world and affect the poorest and most disadvantaged communities. They are acquired by the consumption of eggs, the penetration of larvae as in the case of hookworms and schistosomiasis, the consumption of undercooked meat with the larval phase of cestodes or the bite of mosquitoes in the case of filariae. ${ }^{4}$ In the world, approximately 1.5 billion people, almost $21 \%$ of the population, are infected by soiltransmitted helminths; 200 million people suffer from schistosomiasis and 120 million affected by filariasis. ${ }^{4}$ Helminthiases are widely distributed throughout the tropics and subtropics, especially in subSaharan Africa, Central America, South America, and East Asia.

More than 267 million preschool-age children and more than 568 million school-age children live in areas with intense transmission of these parasites and need treatment and preventive interventions. ${ }^{5}$ Helminthiasis corresponds to a public health problem, especially in developing countries, where poverty, malnutrition, inadequate water sanitation and minimal health care prevail. The highest rates of infection are usually found in children 5 to 15 years of age and women of childbearing age. ${ }^{6}$ People with helminth infections present 
variable symptoms such as transient pruritic lesions on the skin (due to the penetration of hookworm larvae); digestive disorders such as diarrhea (intestinal helminths), foreign body sensation and anal itching, inflammation of the lymphatic tissue with adenopathy and lymphagitis (in the case of filarial infection); hematuria and dysuria (Schistosoma haematobium infection) ${ }^{2}$ but the most serious signs and symptoms are anemia, neurological and systemic damage.

In this vein, the complementarity with Plasmodium infection is evident. Thus, malaria is predominantly found in rural areas of tropical zones, especially those with nearby freshwater sources and whose income depends on agricultural production. ${ }^{7}$ Agricultural practices such as irrigation create favorable conditions for mosquitoes, increasing human exposure to vector-borne diseases; ${ }^{7}$ they also favor the life cycle of many species of helminths by depositing their eggs and larvae in water sources, which simultaneously function as a breeding ground for mosquitoes of the genus Anopheles spp. ${ }^{8}$

This indicates that the risk factors for the development of the disease in some cases may be similar for both infections. The combination of both groups of parasites can deteriorate the individual's health status, especially due to the development of severe anemia and malnutrition. ${ }^{7,9}$ Additionally, the identification of coinfection cases allows health agencies to plan mitigation actions and implement strategies that eliminate the risks of suffering from both diseases. ${ }^{10}$

In addition to the epidemiological and clinical links exposed, in research terms, various studies have shown that communities living in tropical regions of low-income countries have a higher burden of malaria infection; a high prevalence of helminth infections has been documented in these same áreas. ${ }^{10}$ The Plasmodium falciparum infections can occur in association with intestinal helminths such as Ascaris lumbricoides, Trichuris trichura and Hookworms, association with Schistosoma haematobium and Schistosoma mansoni can also be found in endemic areas for these helminths. ${ }^{10}$ This coinfection between helminths and malaria has been described as a result of similar life cycles and modes of infection, as well as adequate environmental factors and human practices that favor the circulation of these parasites, ${ }^{11}$ to which is added the research of their Deleterious physiological links as the cause of nutrient and blood loss. ${ }^{12}$

Despite the above, studies in this field of parasitology are scarce and to date there is no study that groups and summarizes the available evidence, which is of great relevance given that coinfection constitutes a public health problem that is little addressed, and clinically, the effects of polyparasitism on human health are poorly understood, for which an observational study is required to show the magnitude of the problem and the main causal agents. Therefore, the objective of this research was to estimate the global and species-specific prevalence of Plasmodium spp, helminths and their co-infection from studies published in the world scientific literature between 2000 and 2018.

\section{Methods}

Type of study: Systematic review of the literature.

Study search and selection protocol: The identification, screening, selection and inclusion phases of the PRISMA guide (Preferred Reporting Items for Systematic Reviews and Meta-Analyzes) were applied.

Identification: The search terms from the DeCS thesaurus, "Helminthiasis", "Malaria" and "Helminths" were used and also combinatorial with the following terms were included: Plasmodium Vivax; Plasmodium falciparum; Plasmodium malariae; Plasmodium knowlesi; Plasmodium ovale and Plasmodium cynolmogi.
The search was carried out in Pubmed, Science Direct, SciELO, Web of Science, EBSCO/Medline and Google Scholar, using the Boolean AND. Some syntax used were: in SciELO (ti (Helminths AND Malaria)); in Pubmed (Helminthiasis [TitleAbstract]) AND Malaria [TitleAbstract]; in Science Direct: Title, abstract, keywords Helminths Malaria; in Web of Science Title, abstract, keywords Helminthiasis Malaria, in EBSCO TI Helminthiasis AND TI Malaria and in Google Scholar allintitle: Helminthiasis Malaria.

Screening: Based on reading the titles and abstracts of the manuscripts, the following inclusion criteria were applied: a) having the search terms in the title or abstract (in the case of Google Scholar, only the title filter applies), b) publications of research in humans, c) be an original study, and d) whose objective was the prevalence of coinfection between helminths and malaria. No time restrictions were applied retrospectively, the search ended on August 1, 2018.

Choice: Those that met the following exclusion criteria were eliminated: those that were not available, that dealt with a topic other than helminthiasis and malaria, that were prevalence studies without coinfection data, and those in a language other than English, Spanish and Portuguese.

Inclusion: Studies that completed the previous phases were included, the following variables were organized and extracted: title; Author; year; country; the purpose of the study; population (n); description of the population; study groups; sub groups; population with helminths, population with malaria and population with helminth/ malaria coinfection; helminth species and prevalence; Plasmodium spp species and prevalence; prevalence of coinfection and species involved. Diagnostic method for malaria; diagnostic method for helminths.

\section{Reproducibility and evaluation of the methodological quality of the studies}

In this review, the reproducibility in the search and the selection of the publications was guaranteed by applying the protocol on two different occasions, with an interval of one week, while an Excel database was designed for the reproducibility of the information extraction. Which was completed on two different occasions to verify the concordance of the extracted data. A priori it was determined that the discrepancies would be resolved by consensus. To assess the quality of the publications, the 22 criteria of the STROBE guide (Strengthening the Reporting of OBservational studies in Epidemiology) were applied, calculating the percentage of studies that met each of the guide's ítems.

Analysis: A qualitative synthesis was carried out of the predefined variables in the research protocol. Subsequently, the percentage of studies that included data from coinfection between helminths and malaria. The number of helminth-infected subjects infected with Plasmodium spp. and the number of subjects who have coinfection, these data were organized in Excel Office 365 software and analyzed with IBM SPSS Statistics 25.0® software.

\section{Results}

193,182 publications were identified, of which 1,244 included the search terms in the title or abstract, which were reduced to 61 when applying the inclusion and exclusion criteria (Figure 1). The articles presented good methodological quality, meeting more than $15(70 \%)$ of the 22 criteria of the STROBE guideline; However, in some items a low proportion of studies were found that applied them appropriately, such as the calculation of the sample size and the discussion about the limitations of the generalization of results (Figure 2). 


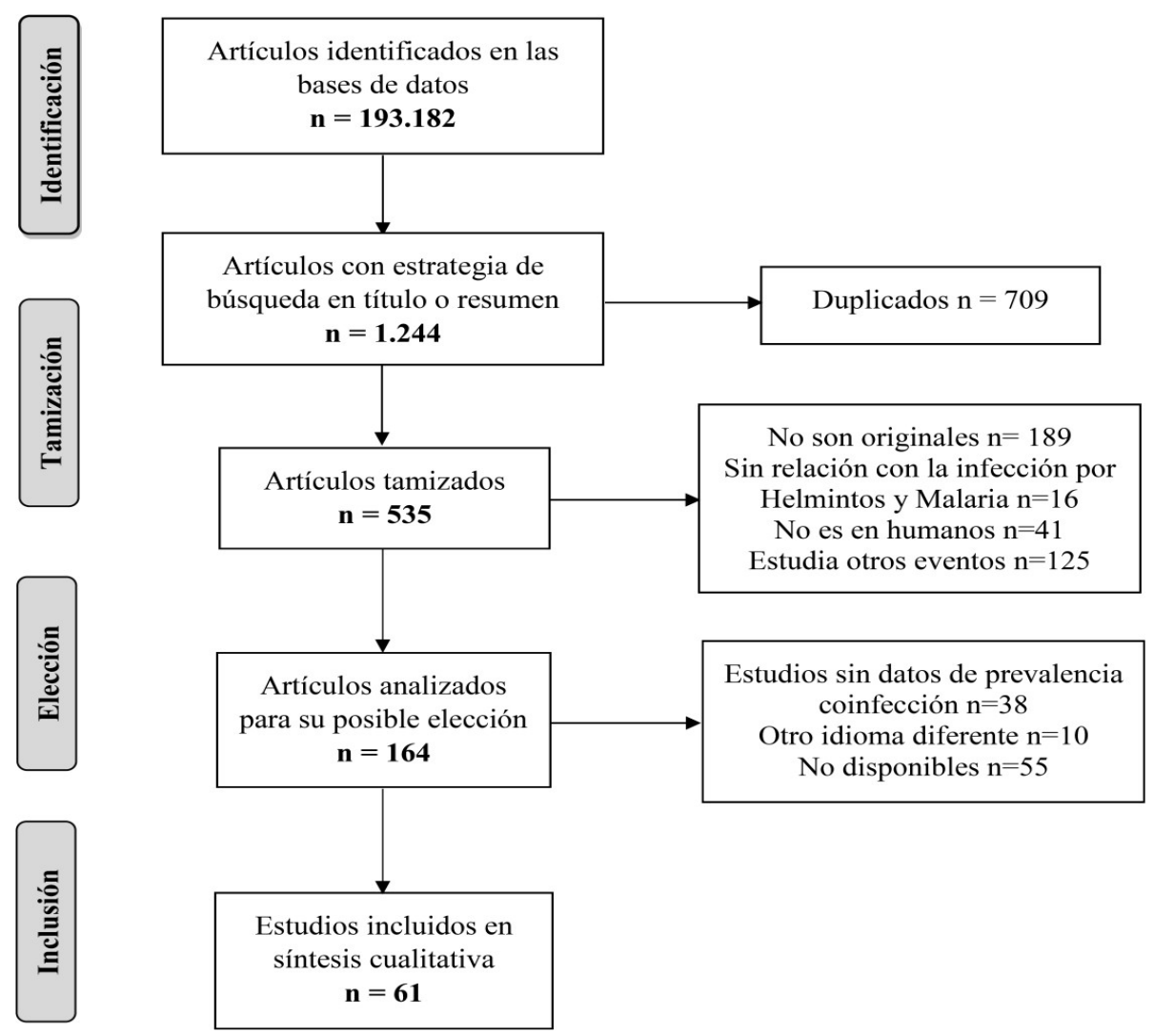

Figure I Study search and selection flowchart. Analysis of the information.

\section{Criterio guía STROBE}

Título/ Resumen

Fundamentación

Objetivo

Diseño del estudio

Contexto

Participantes

Definición de variables

Fuente de datos

Control de sesgos

Tamaño de muestra

Variables cuantitativas

Análisis estadísticos

Resultados de los participantes

Resultados principales

Análisis adicionales

Discusión de resultados clave

Limitaciones

Interpretaciones

Discusión de la generalización

Financiación

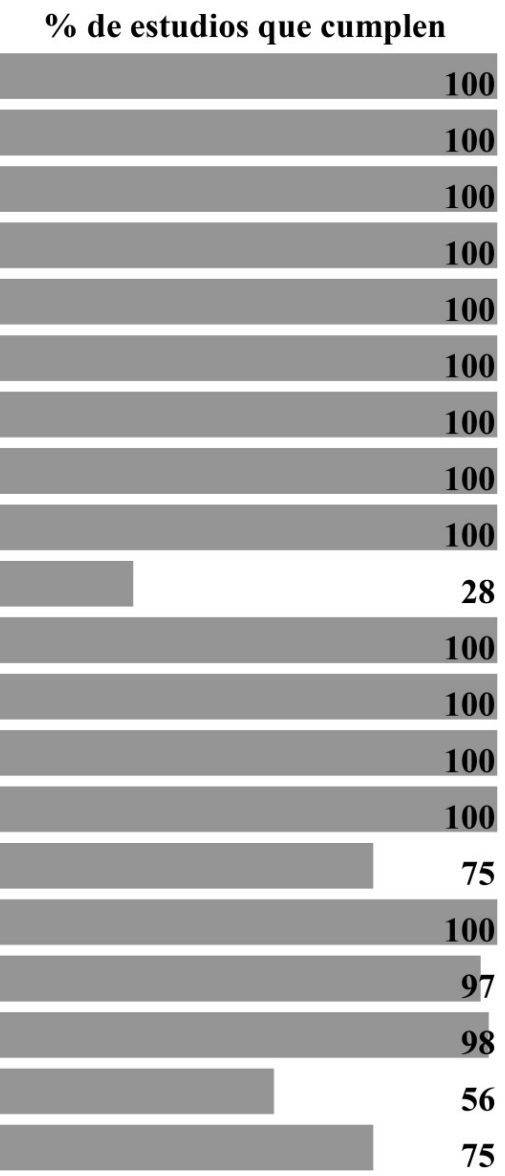

Figure 2 Assessment of methodological quality. Proportion of studies that meet each of the items in the STROBE guide. 
The 61 articles were made between 2000 and 2018, with 45,060 people, mainly from Thailand ( $\mathrm{n}=10$ articles), Nigeria $(\mathrm{n}=8)$ and Ethiopia $(n=8)$; Most of the studies are from the African continent and in America only two studies were found, one from Brazil and the other from Colombia. The populations studied were children (52\%), adults $(36 \%)$ and pregnant women $(18 \%)$, it should be clarified that $7 \%$ of the articles included children and adults. For the analysis, two groups were taken, 51 articles that determined the prevalences of malaria, helminths and its coinfection from the general population and 10 whose population was characterized by having malaria (Table 1).

Table I Description of the included studies according to year, country and population

\begin{tabular}{|c|c|c|c|c|}
\hline Study & Year & Country & Population & $\mathbf{N}$ \\
\hline \multicolumn{5}{|c|}{ General population } \\
\hline Nacher ${ }^{35}$ & 2001 & Tailandia & Adults & 307 \\
\hline Egwunyenga ${ }^{36}$ & 2001 & Nigeria & Pregnant & 2.104 \\
\hline Nacher ${ }^{37}$ & 2002 & Tailandia & Adults & 731 \\
\hline Le Hesran ${ }^{38}$ & 2003 & Senegal & Kids & 105 \\
\hline Shapiro ${ }^{39}$ & 2004 & Uganda & Adults & 1.712 \\
\hline Nkuo ${ }^{40}$ & 2006 & Camerún & Kids & 425 \\
\hline Bejon $^{41}$ & 2008 & Kenia & Kids & 405 \\
\hline Midzi $^{42}$ & 2008 & Zimbabue & Kids & 1.303 \\
\hline Fuseini ${ }^{43}$ & 2009 & Ghana & Pregnant & 300 \\
\hline Yatich $^{44}$ & 2009 & Ghana & Pregnant & 746 \\
\hline Yatich $^{45}$ & 2010 & Ghana & Pregnant & 785 \\
\hline Melo ${ }^{46}$ & 2010 & Brasil & Kids & 216 \\
\hline Sangweme ${ }^{47}$ & 2010 & Zimbabue & Kids & 605 \\
\hline Boel ${ }^{48}$ & 2010 & Tailandia & Pregnant & 829 \\
\hline Yatich ${ }^{34}$ & 2010 & Ghana & Pregnant & 746 \\
\hline Midzi $^{24}$ & 2010 & Zimbabue & Kids & 609 \\
\hline Degarege $e^{22}$ & 2010 & Etiopia & Kids and Adults & 1.802 \\
\hline Ojurongbe ${ }^{49}$ & 2011 & Nigeria & Kids & 117 \\
\hline Idindili: ${ }^{50}$ & 2011 & Tanzania & Adults & 464 \\
\hline Mboera $^{51}$ & 2011 & Tanzania & Kids & 587 \\
\hline Thigpen ${ }^{52}$ & 2011 & Malaui & Pregnant & 1.772 \\
\hline Fernández ${ }^{53}$ & 2012 & Colombia & Kids and Adults & 245 \\
\hline Alemu ${ }^{21}$ & 2012 & Etiopia & Adults & 384 \\
\hline $\operatorname{Ivan}^{54}$ & 2012 & Ruanda & Pregnant & 328 \\
\hline Righetti ${ }^{32}$ & 2012 & Costa de Marfil & Kids & 324 \\
\hline Degarege $\mathrm{e}^{55}$ & 2012 & Etiopia & Adults & 1.065 \\
\hline$K_{i m b i}{ }^{31}$ & 2012 & Camerún & Kids & 443 \\
\hline Mulu ${ }^{56}$ & 2013 & Etiopia & Kids & 463 \\
\hline Ngetich ${ }^{57}$ & 2013 & Kenia & Kids & 356 \\
\hline Getachew $^{58}$ & 2013 & Etiopia & Pregnant & 388 \\
\hline Abanye $\mathrm{e}^{59}$ & 2013 & Nigeria & Niños & 690 \\
\hline Fairley ${ }^{60}$ & 2013 & Kenia & Pregnant & 696 \\
\hline$Y_{a p i}{ }^{61}$ & 2013 & Costa de Marfil & Kids & 5.246 \\
\hline Mulu ${ }^{62}$ & 2014 & Etiopia & Adults & 413 \\
\hline Matangila ${ }^{63}$ & 2014 & El Congo & Kids & 650 \\
\hline
\end{tabular}




\begin{tabular}{|c|c|c|c|c|}
\hline Study & Year & Country & Population & $\mathbf{N}$ \\
\hline \multicolumn{5}{|c|}{ General population } \\
\hline Degarege ${ }^{64}$ & 2014 & Etiopia & Adults & 702 \\
\hline Kinung'hi ${ }^{65}$ & 2014 & Tanzania & Kids & 1.546 \\
\hline Ateba $^{66}$ & 2015 & Gabón & Kids & 125 \\
\hline Ajayi ${ }^{67}$ & 2015 & Nigeria & Kids & 370 \\
\hline Adedoja $^{68}$ & 2015 & Nigeria & Kids & 1.017 \\
\hline Salim 69 & 2015 & Tanzania & Kids & 992 \\
\hline Ndamukong ${ }^{70}$ & 2015 & Camerún & Kids & 1.138 \\
\hline Kepha ${ }^{71}$ & 2015 & Kenia & Kids & 5.471 \\
\hline $\mathrm{Njua}^{72}$ & 2016 & Camerún & Kids & 357 \\
\hline Ateba $^{73}$ & 2016 & Gabón & Kids & 287 \\
\hline Babamale $^{74}$ & 2016 & Nigeria & Pregnant & 300 \\
\hline Marcelline $^{75}$ & 2016 & Ruanda & Kids & 465 \\
\hline Sumbele $e^{76}$ & 2017 & Camerún & Kids and Adults & 450 \\
\hline $\mathrm{Adu}^{77}$ & 2018 & Ghana & Adults & 1.569 \\
\hline Babamale $^{78}$ & 2018 & Nigeria & Kids and Adults & $47 \mid$ \\
\hline Bwanika $^{27}$ & 2018 & Uganda & Kids & 240 \\
\hline \multicolumn{5}{|c|}{ Malaria population } \\
\hline Nacher ${ }^{79}$ & 2000 & Tailandia & Adults & 427 \\
\hline Nacher ${ }^{80}$ & 2001 & Tailandia & Adults & 98 \\
\hline Nacher ${ }^{81}$ & 2001 & Tailandia & Adults & 179 \\
\hline Nacher ${ }^{82}$ & 2001 & Tailandia & Adults & 291 \\
\hline Nacher ${ }^{83}$ & 2002 & Tailandia & Adults & 284 \\
\hline Nacher ${ }^{84}$ & 2004 & Tailandia & Adults & 438 \\
\hline Degarege ${ }^{85}$ & 2009 & Etiopia & Adults & 458 \\
\hline Akanni86 & 2014 & Nigeria & Kids & 292 \\
\hline Othman ${ }^{87}$ & 2014 & Malasia & Adults & 94 \\
\hline Abbate $^{88}$ & 2017 & Tailandia & Adults & 283 \\
\hline
\end{tabular}

In the general population the techniques used for the diagnosis of malaria were thick film, PCR and immunochromatography for P. falciparum, with prevalences of $39.9 \%, 65.9 \%$ and $36.3 \%$, respectively, being P. falciparum the species More frequently. The global prevalence of helminths was $43.4 \%$, using Kato-katz, and the sedimentation technique with formalin-ether for the diagnosis of intestinal helminths, urinary sediment for S. haematobium and for filarias, immunochromatography was used, with prevalences of 34.7 $\%, 29.3 \% 30.1 \%$ and $18.1 \%$, respectively. S. haematobium was the most prevalent agent with $19.9 \%$, followed by filaria with $15.8 \%$. Hookworms were the predominant intestinal helminths (15.5\%) followed by Áscaris Lumbricoides with 13.3\% (Table 2). 
Table 2 Prevalence of malaria and helminths in the general population

\begin{tabular}{|c|c|c|c|}
\hline & Evaluated & Positive & Prevalence \% \\
\hline \multicolumn{4}{|l|}{ Malaria } \\
\hline General frequency & 41.758 & I7.II & 41,0 \\
\hline \multicolumn{4}{|l|}{ By diagnostic technique } \\
\hline Thick drop & 39.57 & 15.779 & 39,9 \\
\hline PCR for Malaria & 983 & 648 & 65,9 \\
\hline Immunochromatography P. falciparum & 1.492 & 542 & 36,3 \\
\hline \multicolumn{4}{|l|}{ By species } \\
\hline Plasmodium falciparum & 34.61 & 12.605 & 36,4 \\
\hline Plasmodium spp. & 8.5 & 2.571 & 30,2 \\
\hline Plasmodium vivax & 5.274 & 610 & 11,6 \\
\hline Plasmodium malariae & 7.858 & 254 & 3,2 \\
\hline P. falciparum + P. vivax & 3.59 & 52 & 1,4 \\
\hline Plasmodium Ovale & 5.104 & 16 & 0,3 \\
\hline \multicolumn{4}{|l|}{ Helmintos } \\
\hline General frequency & 41.758 & 18.115 & 43,4 \\
\hline \multicolumn{4}{|l|}{ By Technique } \\
\hline Kato-Katz & 28.117 & 9.77 & 34,7 \\
\hline Sedimentation with formalin-ether & 8.146 & 2.385 & 29,3 \\
\hline Urinary sedimentation & 9.742 & 2.931 & 30,1 \\
\hline Immunochromatography for filariae & 587 & 106 & 18,1 \\
\hline \multicolumn{4}{|l|}{ By species } \\
\hline S. haematobium & 16.049 & 3.196 & 19,9 \\
\hline W. bancrofti;Very much Mansonella perstans. & 2.275 & 360 & 15,8 \\
\hline Uncinarias & 36.712 & 5.704 & 15,5 \\
\hline Ascaris Lumbricoides & 33.4 & 4.452 & 13,3 \\
\hline Schistosoma Mansoni & 20.55 & 1.79 & 8,7 \\
\hline Trichuris Trichiura & 32.34 & 2.262 & 7,0 \\
\hline Strongyloides stercoralis & 6.239 & 253 & 4,1 \\
\hline Hymenolepis spp. & 5.462 & 207 & 3,8 \\
\hline Enterobius Vermicularis & 7.466 & 157 & 2,1 \\
\hline Taenia spp. & 4.404 & 33 & 0,7 \\
\hline Dicrocoelium spp. & 1.569 & 11 & 0,7 \\
\hline Trichostrongylus spp. & 1.986 & 7 & 0,4 \\
\hline Diphyllobothrium latum & 117 & I & 0,9 \\
\hline
\end{tabular}

Seven individuals infected by Trichostrongylus spp. considered a helminth that infects mainly animals, in this case it can be considered a zoonosis; 11 had infection with Dicrocoelium spp. a trematode that mainly infects cattle but humans can act as an accidental host, and a person infected with Diphyllobothrium latum, a cestode whose life cycle includes fish and humans are infected by eating undercooked meat or raw (Table 3 ). 
Table 3 Prevalence of coinfection in the general population

\begin{tabular}{|c|c|c|c|}
\hline & Evaluated & Positive & Prevalence \% \\
\hline Coinfection Helmintos/Malaria & 41.758 & 7.176 & 17,2 \\
\hline \multicolumn{4}{|l|}{ Plasmodium spp (P. spp.) } \\
\hline P. spp. + A. lumbricoides & 6.475 & 682 & 10,5 \\
\hline P. spp. + Uncinarias & 7.134 & 322 & 4,5 \\
\hline P. spp. + T. trichiura & 6.313 & 312 & 4,9 \\
\hline P. spp. + S. mansoni & 9.79 & 132 & 1,3 \\
\hline P. spp. + Hymenolepis spp. & 4.061 & 49 & 1,2 \\
\hline P. spp. + E. vermicularis & 3.484 & 45 & 1,3 \\
\hline P. spp. + S. stercolaris & 746 & 21 & 2,8 \\
\hline P. spp. + Taenia spp. & 3.673 & 18 & 0,5 \\
\hline P. spp. + S. haematobium & 992 & 2 & 0,2 \\
\hline \multicolumn{4}{|l|}{ Plasmodium falciparum (P.f) } \\
\hline P.f. + W. bancrofti o Loa loa & 587 & 64 & 10,9 \\
\hline P.f. + A. lumbricoides & 13.238 & 978 & 7,4 \\
\hline P.f. + S. haematobium & 12.183 & 845 & 6,9 \\
\hline P.f. + Uncinarias & 22.166 & 1.343 & 6,1 \\
\hline P.f. + S. mansoni & 9.79 & 424 & 4,3 \\
\hline P.f. + T.Trichiura & 11.111 & 451 & 4,1 \\
\hline P.f. + Hymenolepis spp. & 1.017 & 41 & 4,0 \\
\hline P.f. + S. stercolaris & 746 & 14 & 1,9 \\
\hline P.f. + D. latum & 117 & 1 & 0,9 \\
\hline \multicolumn{4}{|l|}{ Poliparasitismo- P. falciparum + } \\
\hline P.f. + A. Lumbricoides + T.Trichiura & 868 & 57 & 6,6 \\
\hline $\begin{array}{l}\text { P.f. + S. haematobium + S.mansoni+ A. } \\
\text { lumbricoides + T. trichiura + Anquilostoma }\end{array}$ & 2.849 & 45 & 1,6 \\
\hline P.f. + S. mansoni + Uncinarias & 1.902 & 28 & 1,5 \\
\hline P.f. + S. haematobium + Uncinarias & 2.133 & 24 & $\mathrm{I}, \mathrm{I}$ \\
\hline P.f. + S. haematobium +W. bancrofti & 587 & 17 & 2,9 \\
\hline P.f. + A. lumbricoides + Uncinarias & 1.168 & 16 & 1,4 \\
\hline P.f. + A. lumbricoides + T. trichiura + & 868 & 9 & 1,0 \\
\hline \multicolumn{4}{|l|}{ Uncinarias } \\
\hline P.f. + T. trichiura + Uncinarias & 868 & 3 & 0,3 \\
\hline \multicolumn{4}{|l|}{ Plasmodium vivax (P. v.) } \\
\hline P. v. + A. lumbricoides & 1.983 & 58 & 2,9 \\
\hline P. v. + Uncinarias & 1.983 & 23 & 1,2 \\
\hline P. v. + T. trichiura & 1.983 & 21 & $\mathrm{I}, \mathrm{I}$ \\
\hline P. v. + S. mansoni & 1.767 & 6 & 0,3 \\
\hline
\end{tabular}

The prevalence between helminth and Plasmodium coinfection was $17.2 \%$, with a higher occurrence of Plasmodium spp. and A. lumbricoides followed by Plasmodium spp. and T. trichiura. Specifically in $P$. falciparum the highest proportion of coinfection was registered with $W$. bancrofti, A. lumbricoides, S. haematobium and hookworms. In the case of $P$. vivax, it was with A. lumbricoides. Multiple infections were also found between helminths and P.falciparum, as is the case of 45 individuals with malaria plus 
infection with five different intestinal helminth species (Table 4). In the articles based on the population with malaria, a global prevalence of helminth of $52 \%$ was found, being higher those that occurred between Plamodium and A. lumbricoides, Uncinarias and T. Trichiura (Table 4).

Table 4 Prevalences in the population with malaria

\begin{tabular}{|c|c|c|c|}
\hline Species & Evaluated & Positive & Prevalence \% \\
\hline Plasmodium spp. & 3.302 & 2.287 & 69,3 \\
\hline Plasmodium falciparum & 1.015 & 558 & 55,0 \\
\hline Plasmodium vivax & 552 & 435 & $\mathbf{7 8 , 8}$ \\
\hline P. falciparum + P. vivax & 552 & 22 & 4,0 \\
\hline Helmintos global & 3.302 & 1.718 & 52,0 \\
\hline Kato-Katz & 1.72 & 790 & 45,9 \\
\hline Sedimentation with formalin-ether & 1.291 & 755 & 58,5 \\
\hline PCR para Helmintos & 94 & 46 & 48,9 \\
\hline \multicolumn{4}{|l|}{ Plasmodium spp } \\
\hline P. spp. + A. lumbricoides & 2.77 & 1.284 & 46,4 \\
\hline P. spp. + Uncinarias & 2.052 & 1.004 & 48,9 \\
\hline P. spp. + T.Trichiura & 2.343 & 627 & 26,8 \\
\hline P. spp. + S. stercoralis & 844 & 229 & 27,1 \\
\hline P. spp. + S. Mansoni & 292 & 8 & 2,7 \\
\hline \multicolumn{4}{|l|}{ Plasmodium falciarum } \\
\hline P.f. + Uncinarias & 557 & 156 & 28,0 \\
\hline P. f. + A. lumbricoides & 754 & 136 & 18,0 \\
\hline P.f. + S. stercolaris & 848 & 89 & 10,5 \\
\hline P.f. + T.Trichiura & 754 & 169 & 22,4 \\
\hline \multicolumn{4}{|l|}{ Plasmodium vivax + } \\
\hline P. v. + S. stercoralis & 94 & 12 & 12,8 \\
\hline P.v. + Uncinarias & 94 & 11 & 11,7 \\
\hline P. v. + A. lumbricoides & 94 & 2 & 2,1 \\
\hline
\end{tabular}

In seven studies that determined the prevalence of thick gout malaria in 4,995 pregnant women, a prevalence of Plasmodiumintestinal helminth coinfection of $15.4 \%(95 \% \mathrm{CI}=14.4-16.4)$ was found, with studies reporting co-infection in a range between $7.7 \%$
$(95 \% \mathrm{CI}=4.9-10.5)$ and $18.7 \%(95 \% \mathrm{CI}=17.0-20.4)($ Figure 3$)$; being more relevant the coninfection of Plasmodium with A. lumbricoides with a prevalence of $8.0 \%(95 \% \mathrm{CI}=7.0-9.0)$, and unicinary with $12.4 \%(95 \% \mathrm{CI}=11.5-13,4)$.

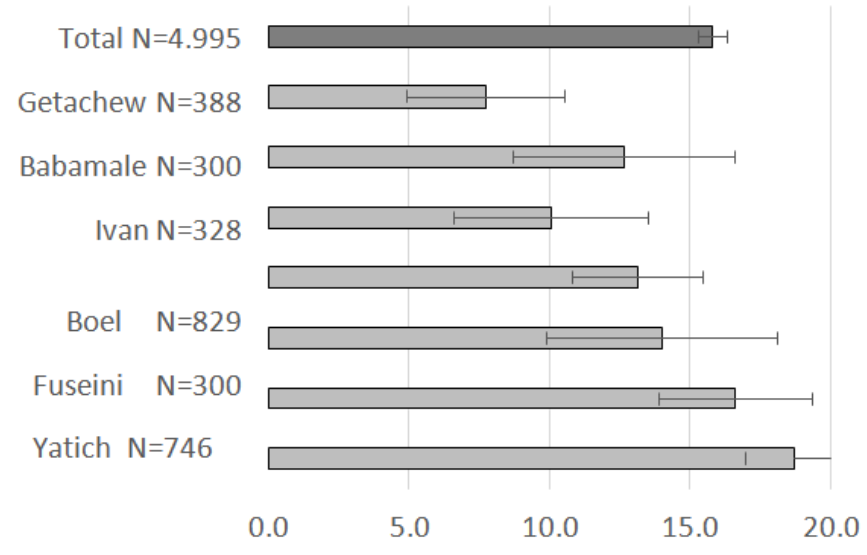

Figure 3 Meta-analysis of the prevalence of malaria (thick blood film) and intestinal helminths (Kato-Katz or Formol-ether) in pregnant women. 
Similarly to what was found for pregnant women, in 25 studies that determined the prevalence of malaria with thick gout in 23,680 children, a prevalence of Plasmodium-intestinal helminth coinfection of $17.1 \%$ was found $(95 \% \mathrm{CI}=16.6-17,6)$ (Figure 4$)$.

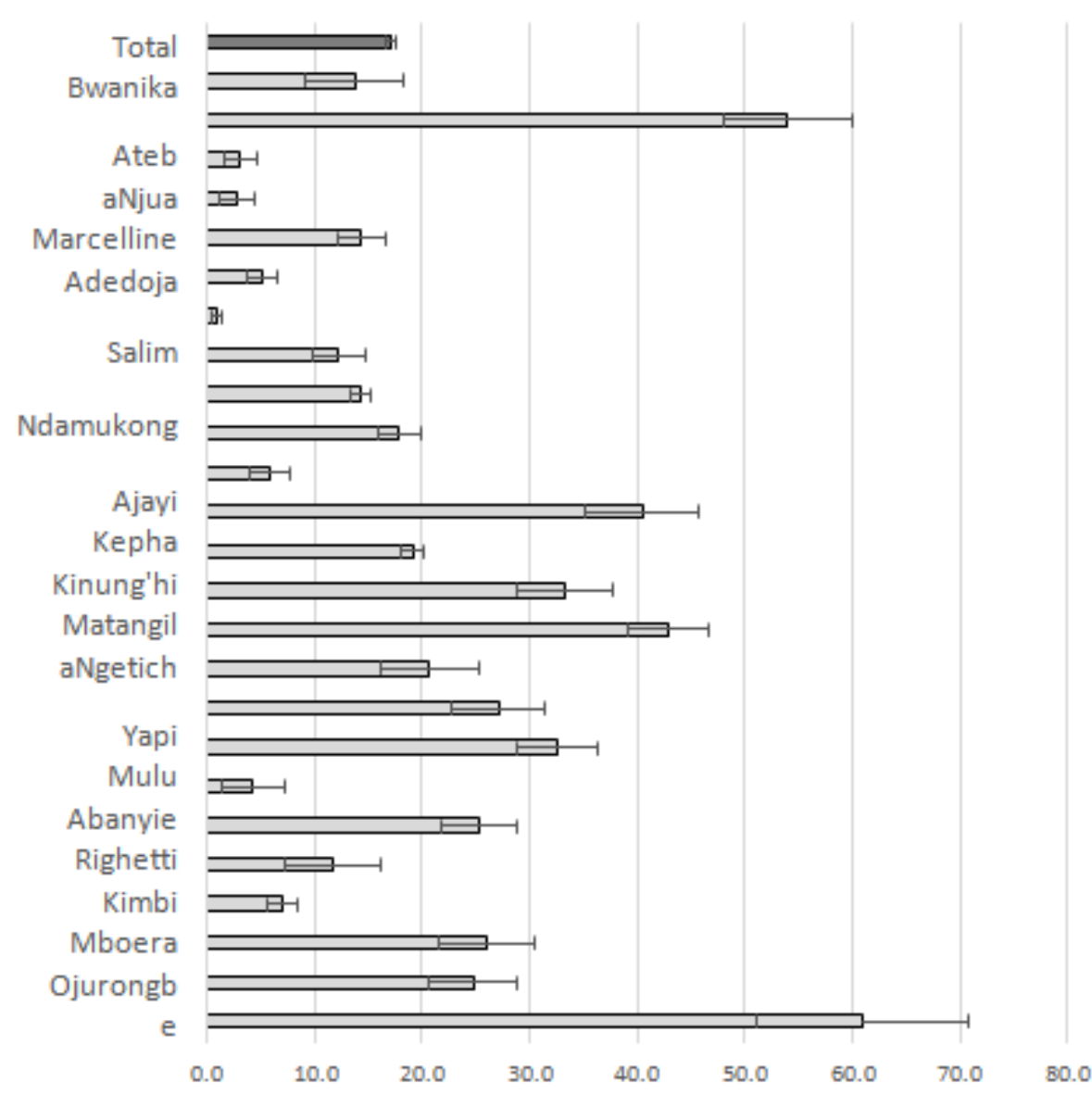

Figure 4 Meta-analysis of the prevalence of malaria (thick blood film) and intestinal helminths (Kato-Katz or Formol-ether) in children.

\section{Discussion}

Malaria is a disease that can occur in association with different types of helminths, especially with soil-transmitted helminths or intestinal helminths (A. lumbricoides, T. trichiura and Uncinarias) which infect a third of the world population, ${ }^{5}$ or schistosomes such as $S$. haematobium and $S$. mansoni which are endemic helminths in tropical areas especially in Africa and East Asia and co-infections have been associated with $P$. falciparum. ${ }^{13}$

Coinfection between helminths and malaria occurs as a result of similar life cycles and environmental factors conducive to the transmission of both, such as the presence of malaria in the population near water sources where Anopheles spp. reproduces, which can be associated with the presence of helminth eggs and larvae in these sources, which many people can use for their consumption or domestic activities. ${ }^{12}$ To this must be added insufficient material living conditions, or the concentration of the population living in poverty in endemic areas for both types of infection, among other frequent situations in Africa, South America and East Asia.

\section{Global prevalence of malaria}

In this review, a malaria prevalence of $41 \%$ was found in the three indicated regions, this can be explained taking into account the world malaria report carried out by the WHO in 2017, which reported 216 million cases of malaria, in this report Africa reported 194 million cases, followed by East Asia with 14.6 million and South America with 875 thousand reported cases. ${ }^{14}$ The global distribution of malaria lists a prevalence in South America between 10 and 11\%, in East Asia it is considered between 11 and $50 \%$, while Africa has a prevalence greater than $50 \%{ }^{15}$ corresponding to the continent with the highest number of reported cases.

It has been considered that P.falciparum and P.vivax are the Plasmodium species implicated in most cases of malaria, ${ }^{15}$ a situation that is confirmed by the prevalence of both species in this review, where $36.4 \%$ were found for P. falciparum and $11.6 \%$ for P.vivax. This result is also consistent with the number of malaria cases worldwide; For example, in Africa $99.7 \%$ of malaria cases were caused by $P$. falciparum, in East Asia $P$. falciparum corresponds to $66 \%$ of cases and $P$. vivax to $34 \%$, while in the region of the In the Americas, the situation is the opposite since $P$. vivax corresponds to $64 \%$ of the cases. ${ }^{14}$

\section{Global prevalence of helminths}

In this review, the prevalence of helminths was $43.4 \%$ in which the majority of helminthiasis cases correspond to soil-transmitted helminths. Soil-transmitted helminths are considered to be responsible for the majority of helminthiasis cases in the world, only in Africa the prevalence of soil-transmitted helminths is $24.7 \%{ }^{16}$ and in the world 
almost $24 \%$ of the population is infected by Ascaris lumbricoides; Trichuris trichiura and Hookworms (Necator americanus and Ancylostoma duodenale). ${ }^{5}$ It is estimated that A. lumbricoides is present in approximately 1,450 million people in the world, the Hookworms in 1,300 million and T. trichura in 1,050 million people. ${ }^{17}$ In this review, the distribution of $A$. lumbricoides is different from that reported worldwide since a prevalence of $10.7 \%$ was found, lower than the Uncinaries (15.5\%), this difference can be explained because most of the population included in this review come from the African continent where these species present prevalences of $16.5 \%$ for Uncinarias, $6.6 \%$ for A. lumbricoides and $4.4 \%$ for T. trichiura. ${ }^{16}$

Schistosomiasis is an acute and chronic parasitic disease caused by trematodes of the genus Schistosoma and in this review it corresponds to the most prevalent helminth species after soil-transmitted helminths. In the world, schistosomiasis affects approximately 206.5 million people ${ }^{18}$ and the species of helminths are distributed throughout the tropical area, where Africa presents the majority of cases of infection and is the only continent that presents circulation of $S$. haematobium ${ }^{19}$ this would explain the fact that this species was the most prevalent in this review with $19.9 \%$.

\section{Prevalence of coinfection between helminths and malaria and its effects on human health}

Helminths and Plasmodium spp. share the same geographic distribution and can affect the same population, cases of coinfection between malaria and helminths occur mainly in the tropics such as South America, Africa and East Asia, ${ }^{20}$ this explains why in this review it was found that the prevalence of relatively high coinfection with $17.2 \%$, where the evaluated population come from these areas. In addition, the analysis by species showed that the highest prevalence of coinfection found in this review was between P. falciparum - A. lumbricoides and P. falciparum - S. haematobium, which could be attributed to the epidemiological nexus of these agents, which are distributed in a similar way in the same tropical territory. ${ }^{20}$ Regarding the impact of helminth-malaria co-infection on human health, there are several studies that have contradictory results. Malaria and soil-transmitted helminth infections contribute to the prevalence of anemia, being more severe in individuals who are simultaneously infected with malaria and helminths. ${ }^{21-23}$

In contrast, other studies have reported that coinfection between malaria and intestinal helminths does not affect hemoglobin values; however, hookworms are known to be associated with anemia due to their hematophagous character, as well as schistosomes due to their invasion into tissues and damage to multiple organs. ${ }^{24,25}$

Immunologically, it has been found that co-infection between helminths and malaria have a different effect on cytokine production and cellular response to single infections by both parasites. During co-infections with malaria, an immunomodulatory effect of helminths has been reported, a potential mechanism would be the production of IL-10 by helminth infection, which could protect against severe malaria. ${ }^{26}$ Bwanika et al. Found that IL-10 levels were higher in subjects coinfected by malaria and helminths compared to subjects with a single $P$. falciparum infection; ${ }^{27}$ Other studies indicate that the production of IL-10 favors the sequestration of parasitized red blood cells, which is why it can be protective against malaria, reducing the risk of complications. ${ }^{7}$

Coinfection between malaria and helminths can also cause a change in the immune response from Th1 to Th2, a polyclonal activation of B cells, and the production of cytokines such as IL-4 and
IL-6, increasing IgE synthesis. ${ }^{28}$ Consequently, coinfection between malaria and helminths appears to increase serum IgE levels; this elevated IgE concentration was associated with a low P. falciparum parasite load in subjects with coinfection compared to subjects with malaria alone. ${ }^{29}$ During coinfection by helminths and malaria, helminths have been found to have a protective factor against malaria complicated by stimulating an inflammatory response. ${ }^{29}$

\section{Populations most at risk of coinfection between helminths and malaria}

Taking into account that the population included in the study comes from tropical countries, it can also be considered that people living in rural areas where the economy is based on agriculture have a greater risk of acquiring co-infection between helminths and malaria; ${ }^{30}$ due to a greater risk of contact with the vector and infective forms of helminths, since these areas are characterized by greater stagnation of water, dense bushes around houses, lower level of education, poverty and lack of preventive measures effective against malaria, or the type of housing that predominates in rural areas, being made of planks, cracks or other characteristics conducive to the vector. ${ }^{31}$

School-age children from tropical countries such as Africa and South America have a higher prevalence (36\%) of coinfection between helminths and malaria, compared to the adult population $(13.4 \%))^{32}$ This added to the fact of having greater risk behaviors such as contact with the ground, swimming or walking in fresh water such as rivers and lakes (risk behavior for Schistosoma spp), consumption of uncooked food, untreated water and greater risk for other conditions health problems such as malnutrition. ${ }^{6}$ For example, Righett et al found that early school-age children living in remote rural areas are at increased risk of coinfection between P. falciparum and Uncinarias due to poor hygiene, ecological conditions suitable for the life cycles of the parasites and difficult access to healthcare facilities for people living in this environment. ${ }^{32}$

Another population at risk of helminth infection and malaria are pregnant women due to the immunosuppressive nature of pregnancy and some frequent risk behaviors in women from poor areas, such as a diet low in iron and other nutrients. ${ }^{33}$ For this reason, pregnant women presented a high prevalence of helminth/malaria coinfection, which has been shown in analytical studies that have compared this group with women who are not pregnant, ${ }^{32}$ increasing the risks to the health of the mother and the mother. The newborn as an increased risk of anemia, premature pregnancies and low birth weight. ${ }^{34}$

\section{Conclusion}

A high prevalence of coinfection was found in a low number of studies, which shows that the study of interactions between Plasmodium and helminths constitutes an underdeveloped area in parasitology. Despite the high magnitude of malaria and helminths in America, studies of coinfection in the region are scarce, which constitutes an obstacle to avoid its clinical and epidemiological effects, while preventing the development of public policies for parasitological control in endemic areas. It is necessary to design health programs to prevent and control malaria and helminthiasis, and in the Latin American case, increase epidemiological investigations on the magnitude of coinfection, etiological studies to identify the factors and groups at higher risk, as well as the design and evaluation of interventions aimed at both health problems in endemic areas.

\section{Acknowledgments}

None. 


\section{Conflicts of interest}

None of the authors declare a conflict of interest for the publication of this manuscript.

\section{References}

1. WHO Media centre. Paludismo: Datos y cifras. Ginebra Suiza: OMS malaria; 2018.

2. Botero D, Restrepo M. Parasitosis humanas. Medellin: Corporacion para Investigaciones Biologicas; 2012.

3. World Health Organization. Puntos clave: Informe mundial sobre el paludismo 2017. WHO: Ginebra Suiza; 2017.

4. WHO Media centre. La Organización Mundial de la Salud y un conjunto de colaboradores dan a conocer un nuevo plan coordinado para tratar a millones de personas que sufren enfermedades tropicales desatendidas [Internet]. Ginebra Suiza: WHO; 2013.

5. WHO Media centre. Helmintiasis transmitidas por el suelo. Ginebra Suiza: WHO; 2018.

6. WHO Media centre. Prevención y control de la esquistosomiasis y las helmintiasis transmitidas por el suelo. Ginebra Suiza: WHO; 2004.

7. Layland LE, Specht S. Helpful or a Hindrance: Co-infections with Helminths During Malaria. Adv Exp Med Biol. 2014;828:99-129.

8. Mboera LEG, Senkoro KP, Rumisha SF, et al. Plasmodium falciparum and helminth coinfections among schoolchildren in relation to agroecosystems in Mvomero District, Tanzania. Acta Trop. 2011;120(12):95-102.

9. Adegnika AA, Kremsner PG. Epidemiology of malaria and helminth interaction: a review from 2001 to 2011. Curr Opin HIV AIDS. 2012;7(3):221-224.

10. Wilson S, Dunne DW. Advances in our understanding of the epidemiology of Plasmodium and schistosome infection: Informing coinfection studies. Curr Opin HIV AIDS. 2012;7(3):225-230.

11. Mwangi TW, Bethony J, Brooker S. Malaria and helminth interactions in humans: an epidemiological viewpoint. Ann Trop Med Parasitol. 2006;47(2):551-570.

12. Ayi Irene, Kwamena Tetteh, Otchere J. Poly-parasitism of Plasmodium Falciparum and Helminths Among School Children in Three Peri-urban Communities in Ghana. In: Towards Effective Disease Control in Ghana. Five Legon: Sub-Saharan Publishers; 2014. 173-174 p.

13. Onkoba NW, Chimbari MJ, Mukaratirwa S. Malaria endemicity and coinfection with tissue-dwelling parasites in Sub-Saharan Africa: A review. Infect Dis Poverty. 2015;4:35.

14. WHO Media centre. World malaria report 2017. Ginebra Suiza: WHO; 2017.

15. Snow RW, Guerra CA, Noor AM, et al. The global distribution of clinical episodes of Plasmodium falciparum malaria. Nature. 2005;434(7030):214-217.

16. Biedermann P, Ekpo UF, Garba A, et al. Spatial and temporal distribution of soil-transmitted helminth infection in sub-Saharan Africa : a systematic review and geostatistical meta-analysis. Lancet Infect Dis. 2015;15(1):7484.

17. Savioli L, Albonico M. Soil-transmitted helminthiasis. Nature Reviews Microbiology. 2004;2(8):618-619.

18. WHO Media centre. Esquistosomiasis. World malaria report 2017. Ginebra Suiza: WHO; 2018. 1-3 p.

19. Colley DG, Bustinduy AL, Secor WE, et al. Human schistosomiasis. Lancet. 2014;383(9936):2253-2264.
20. Adegnika AA, Kremsner PG. Epidemiology of malaria and helminth interaction: A review from 2001 to 2011. Curr Opin HIV AIDS. 2012;7(3):221-224.

21. Alemu A, Shiferaw Y, Ambachew A, et al. Malaria helminth co-infections and their contribution for aneamia in febrile patients attending Azzezo health center, Gondar, Northwest Ethiopia: a cross sectional study. Asian Pac J Trop Med. 2012;5(10):803-809.

22. Degarege A, Animut A, Legesse M, et al. Malaria and helminth coinfections in outpatients of Alaba Kulito Health Center, southern Ethiopia: a cross sectional study. BMC Res Notes. 2010;3:143.

23. Achidi EA, Apinjoh TO, Mbunwe E, et al. Febrile status, malarial parasitaemia and gastro-intestinal helminthiases in schoolchildren resident at different altitudes, in south-western Cameroon. Ann Trop Med Parasitol. 2008;102(2):103-118.

24. Midzi N, Mtapuri-Zinyowera S, Mapingure MP, et al. Consequences of polyparasitism on anaemia among primary school children in Zimbabwe. Acta Trop. 2010;115(1-2):103-111.

25. Kinung'hi SM, Magnussen P, Kaatano GM, et al. Malaria and helminth co-infections in school and preschool children: a cross-sectional study in Magu district, north-western Tanzania. PLoS One. 2014;9(1):e86510.

26. Wammes LJ, Hamid F, Wiria AE, et al. Regulatory $\mathrm{T}$ cells in human geohelminth infection suppress immune responses to BCG and Plasmodium falciparum. Eur J Immunol. 2010;40(2):437-442.

27. Bwanika R, Kato CD, Welishe J, et al. Cytokine profiles among patients co- infected with Plasmodium falciparum malaria and soil borne helminths attending Kampala International University Teaching Hospital, in Uganda. Allergy Asthma Clin Immunol. 2018;14:10.

28. Mulu A, Kassu A, Legesse M, et al. Helminths and malaria co-infections are associated with elevated serum IgE. Parasit Vectors. 2014;7(1):240.

29. Mulu A, Kassu A, Legesse M, et al. Helminths and malaria coinfections are associated with elevated serum IgE. Parasites and Vectors. 2014; $7(1): 240$.

30. Mwangi TW, Bethony JM, Brooker S. Malaria and helminth interactions in humans: an epidemiological viewpoint. Ann Trop Med Parasitol. 2006;100(7):551-570.

31. Kimbi H, Lum E, Wanji S. Co-infections of asymptomatic malaria and soil-transmitted helminths in school children in localities with different levels of urbanization in the Mount Cameroon. J Bacteriol Parasitol. 2012;3:2.

32. Righetti AA, Glinz D, Adiossan LG, et al. Interactions and Potential Implications of Plasmodium falciparum-Hookworm Coinfection in Different Age Groups in South-Central Côte d'Ivoire. PLoS Negl Trop Dis. 2012;6(11):e1889.

33. Wirth J, Rajabov T, Petry N, et al. Micronutrient Deficiencies, Overand Undernutrition, and Their Contribution to Anemia in Azerbaijani Preschool Children and Non-Pregnant Women of Reproductive Age. Nutrients. 2018;10(10):1483.

34. Yatich NJ, Jolly PE, Funkhouser E, et al. The effect of malaria and intestinal helminth coinfection on birth outcomes in Kumasi, Ghana. Am J Trop Med Hyg. 2010;82(1):28-34.

35. Nacher M, Singhasivanon P, Silachamroon U, et al. Association of helminth infections with increased gametocyte carriage during mild falciparum malaria in Thailand. Am J Trop Med Hyg. 2001;65(5):644647.

36. Egwunyenga AO, Ajayi JA, Nmorsi OP, et al. Plasmodium/intestinal helminth co-infections among pregnant Nigerian women. Mem Inst Oswaldo Cruz. 2001;96(8):1055-1059.

37. Nacher M, Singhasivanon P, Yimsamran S, et al. Intestinal helminth infections are associated with increased incidence of Plasmodium falciparum malaria in Thailand. J Parasitol. 2002;88(1):55-58. 
38. Le Hesran JY, Akiana J, Ndiaye EHM, et al. Severe malaria attack is associate with high prevalence of Ascaris lumbricoides infection among children in rural Senegal. Trans R Soc Trop Med Hyg. 2004;98(7):397399.

39. Shapiro AE, Tukahebwa EM, Kasten J, et al. Epidemiology of helminth infections and their relationship to clinical malaria in southwest Uganda. Trans R Soc Trop Med Hyg. 2005;99(1):18-24.

40. Nkuo-Akenji TK, Chi PC, Cho JF, et al. Malaria and helminth co-infection in children living in a malaria endemic setting of mount Cameroon and predictors of anemia. J Parasitol. 2006;92(6):1191-1195.

41. Bejon P, Mwangi TW, Lowe B, et al. Helminth infection and eosinophilia and the risk of Plasmodium falciparum malaria in 1- to 6-year-old children in a malaria endemic area. PLoS Negl Trop Dis. 2008;2(1):e164.

42. Midzi N, Sangweme D, Zinyowera S, et al. The burden of polyparasitism among primary schoolchildren in rural and farming areas in Zimbabwe. Trans R Soc Trop Med Hyg. 2008;102(10):1039-1045.

43. Fuseini G, Edoh D, Kalifa BG, et al. Plasmodium and intestinal helminths distribution among pregnant women in the Kassena-Nankana District of Northern Ghana. J Entomol Nematol. 2009;1(2):19-24.

44. Yatich NJ, Yi J, Agbenyega T, et al. Malaria and intestinal helminth coinfection among pregnant women in Ghana: prevalence and risk factors. Am J Trop Med Hyg. 2009;80(6):896-901.

45. Yatich NJ, Funkhouser E, Ehiri JE, et al. Malaria, intestinal helminth and other risk factors for stillbirth in Ghana. Infect Dis Obstet Gynecol. 2010;2010:350763

46. Melo GC, Reyes-Lecca RC, Vitor-Silva S, et al. Concurrent helminthic infection protects schoolchildren with Plasmodium vivax from anemia. PLoS One. 2010;5(6):e11206.

47. Sangweme DT, Midzi N, Zinyowera-Mutapuri S, et al. Impact of schistosome infection on plasmodium falciparum malariometric indices and immune correlates in school age children in burma valley, zimbabwe. PLoS Negl Trop Dis. 2010;4(11):e882.

48. Boel M, Carrara VI, Rijken M, et al. Complex Interactions between soil-transmitted helminths and malaria in pregnant women on the ThaiBurmese border. PLoS Negl Trop Dis. 2010;4(11):e887.

49. Ojurongbe O, Adegbayi AM, Bolaji OS, et al. Asymptomatic falciparum malaria and intestinal helminths co-infection among school children in Osogbo, Nigeria. J Res Med Sci. 2011;16(5):680-686.

50. Idindili B, Jullu B, Hattendorf J, et al. HIV and parasitic co-infections among patients seeking care at health facilities in Tanzania. Tanzan $J$ Health Res. 2011;13(4):75-85.

51. Mboera LEG, Senkoro KP, Rumisha SF, et al. Plasmodium falciparum and helminth coinfections among schoolchildren in relation to agroecosystems in Mvomero District, Tanzania. Acta Trop. 2011;120(12):95-102.

52. Thigpen MC, Filler SJ, Kazembe PN, et al. Associations between peripheral Plasmodium falciparum malaria parasitemia, human immunodeficiency virus, and concurrent helminthic infection among pregnant women in Malawi. Am J Trop Med Hyg. 2011;84(3):379-385.

53. Fernández-Niño JA, Idrovo AJ, Cucunubá ZM, et al. Paradoxical associations between soil-transmitted helminths and Plasmodium falciparum infection. Trans R Soc Trop Med Hyg. 2012;106(11):701-708.

54. Ivan E, Crowther NJ, Rucogoza AT, et al. Malaria and helminthic coinfection among HIV-positive pregnant women: Prevalence and effects of antiretroviral therapy. Acta Trop. 2012;124(3):179-184.

55. Degarege A, Legesse M, Medhin G, et al. Malaria and related outcomes in patients with intestinal helminths: a cross-sectional study. BMC Infect Dis. 2012;12:291.

56. Mulu A, Legesse M, Erko B, et al. Epidemiological and clinical correlates of malaria-helminth co-infections in Southern Ethiopia. Malar $J$ $2013 ; 12: 227$
57. Ngetich EC, Kihara JH, Odhiambo RO, et al. The Burden of Multiple Infections with Plasmodium Falciparum, Schistosoma Mansoni and Soiltransmitted Helminths among School Going Children in Kisumu, Kenya. Science Journal of Medicine and Clinical Trials. 2013;2013:1-8.

58. Getachew M, Tafess K, Zeynudin A, et al. Prevalence soil transmitted helminthiasis and malaria co-infection among pregnant women and risk factors in Gilgel Gibe Dam area, southwest Ethiopia. BMC Res Notes. 2013;6:263.

59. Abanyie FA, McCracken C, Kirwan P, et al. Ascaris co-infection does not alter malaria-induced anaemia in a cohort of Nigerian preschool children. Malar J. 2013;12:1

60. Fairley JK, Bisanzio D, King $\mathrm{CH}$, et al. Birthweight in offspring of mothers with high prevalence of helminth and malaria infection in coastal Kenya. Am J Trop Med Hyg. 2013;88(1):48-53.

61. Yapi RB, Hürlimann E, Houngbedji CA, et al. Infection and Co-infection with Helminths and Plasmodium among School Children in Côte d'Ivoire: Results from a National Cross-Sectional Survey. PLoS Negl Trop Dis. 2014;8(6):e2913.

62. Mulu A, Kassu A, Legesse M, et al. Helminths and malaria co-infections are associated with elevated serum IgE. Parasit Vectors. 2014;7:240.

63. Matangila JR, Doua JY, Linsuke S, et al. Malaria, schistosomiasis and soil transmitted helminth burden and their correlation with anemia in children attending primary schools in Kinshasa, Democratic Republic of Congo. PLoS One. 2014;9(11):e110789.

64. Degarege A, Animut A, Legesse M, et al. Malaria and helminth coinfection and nutritional status of febrile patients in Southern Ethiopia. $J$ Infect Public Health. 2014;7(1):32-37.

65. Kinunghi SM, Magnussen P, Kaatano GM, et al. Malaria and helminth co-infections in school and preschool children: A cross-sectional study in Magu district, North-Western Tanzania. PLoS One. 2014;9(1):e86510.

66. Ateba-Ngoa U, Adegnika AA, Zinsou JF, et al. Cytokine and chemokine profile of the innate and adaptive immune response of schistosoma haematobium and plasmodium falciparum single and co- infected schoolaged children from an endemic area of Lambaréné, Gabon. Malar J. 2015;14:94

67. Ajayi IO, Afonne C, Dada-Adegbola H, et al. Prevalence of Asymptomatic Malaria and Intestinal Helminthiasis Co-infection among Children Living in Selected Rural Communities in Ibadan Nigeria. Am J Epidemiol Infect Dis. 2015;3(1):15-20.

68. Adedoja A, Tijani BD, Akanbi AA, et al. Co-endemicity of Plasmodium falciparum and Intestinal Helminths Infection in School Age Children in Rural Communities of Kwara State Nigeria. PLoS Negl Trop Dis. 2015;9(7):e0003940.

69. Salim N, Knopp S, Lweno O, et al. Distribution and risk factors for Plasmodium and helminth co-infections: a cross-sectional survey among children in Bagamoyo district, coastal region of Tanzania. PLoS Negl Trop Dis. 2015;9(4):e003660.

70. Ndamukong-Nyanga J, Kimbi H, Sumbele I, et al. A Cross-sectional Study on the Influence of Altitude and Urbanisation on Co-infection of Malaria and Soil-transmitted Helminths in Fako Division, South West Cameroon. Int J Trop Dis Heal. 2015;8(4):150-164.

71. Kepha S, Nuwaha F, Nikolay B, et al. Epidemiology of coinfection with soil transmitted helminths and Plasmodium falciparum among school children in Bumula District in western Kenya. Parasit Vectors. 2015;8:314.

72. Njua-Yafi C, Achidi EA, Anchang-Kimbi JK, et al. Malaria, helminths, co-infection and anaemia in a cohort of children from Mutengene, south western Cameroon. Malar J. 2016;15:69.

73. Ateba-Ngoa U, Jones S, Zinsou JF, et al. Associations Between Helminth Infections, Plasmodium falciparum Parasite Carriage and Antibody Responses to Sexual and Asexual Stage Malarial Antigens. Am J Trop Med Hyg. 2016;95(2):394-400. 
74. Babamale OA, Shittu O, Danladi YK, et al. Pattern of Plasmodiumintestinal helminth co-infection among pregnant women in a high transmission zone of malaria in Nigeria. Asian Pacific $J$ Trop Dis. 2016;6(6):424-428.

75. Marcelline U, Noella U, Tharcisse M, et al. The Impact of Malaria and Gastrointestinal Helminthiasis Co-infection on Anaemia and Severe Malaria among Children in Bugesera District, Rwanda. Int J Trop Dis Heal. 2016;13(4):1-7.

76. Sumbele IUN, Nkemnji GB, Kimbi HK. Soil-transmitted helminths and plasmodium falciparum malaria among individuals living in different agroecosystems in two rural communities in the mount Cameroon area: a cross-sectional study. Infect Dis poverty. 2017;6(1):67.

77. Adu-Gyasi D, Asante KP, Frempong MT, et al. Epidemiology of soil transmitted Helminth infections in the middle-belt of Ghana, Africa. Parasite Epidemiol Control. 2018;3(3):e00071.

78. Babamale OA, Ugbomoiko US, Heukelbach J. High prevalence of Plasmodium falciparum and soil-transmitted helminth co-infections in a periurban community in Kwara State, Nigeria. J Infect Public Health. 2018;11(1):48-53.

79. Nacher M, Gay F, Singhasivanon P, et al. Ascaris lumbricoides infection is associated with protection from cerebral malaria. Parasite Immunol. 2000;22(3):107-113.

80. Nacher M, Singhasivanon P, Treeprasertsuk S, et al. Intestinal helminths and malnutrition are independently associated with protection from cerebral malaria in Thailand. Ann Trop Med Parasitol. 2002;96(1):5-13.

81. Nacher M, Singhasivanon P, Silachamroon U, et al. Helminth infections are associated with protection from malaria-related acute renal failure and jaundice in Thailand. Am J Trop Med Hyg. 2001;65(6):834-836.
82. Nacher M, Singhasivanon P, Gay F, et al. Association of helminth infection with decreased reticulocyte counts and hemoglobin concentration in Thai falciparum malaria. Am J Trop Med Hyg. 2001;65(4):335-337.

83. Nacher M, Singhasivanon P, Traore B, et al. Helminth infections are associated with protection from cerebral malaria and increased nitrogen derivatives concentrations in Thailand. Am J Trop Med Hyg. 2002;66(3):304-309.

84. Nacher M, Treeprasertsuk S, Singhasivanon P, et al. Association of intestinal helminths with decreased liver size and SCD23 concentration during falciparum malaria. Southeast Asian J Trop Med Public Health. 2004;35(1):31-34.

85. Degarege A, Animut A, Legesse M, et al. Malaria severity status in patients with soil-transmitted helminth infections. Acta Trop. 2009;112(1):8-11.

86. Akanni E, Adefioye O. Akanni R, et al. Iron deficiency anaemia associated with helminths and asymptomatic malaria infections among rural school children in southwestern nigeria. Asian Pacific Journal of Tropical Disease. 2014;4(Suppl 2):S590-S594.

87. Othman N, Basuni M, Muhi J, et al. Soil-transmitted helminth infections among malaria patients determined by microscopy and real-time PCR methods at two district hospitals in Sarawak, Malaysia. Trop Biomed. 2015;32(4):710-716.

88. Abbate JL, Ezenwa VO, Guégan JF, et al. Disentangling complex parasite interactions: Protection against cerebral malaria by one helminth species is jeopardized by co-infection with another. PLoS Negl Trop Dis. 2018;12(5):e0006483. 